And, as the editor explains in the preface, the cytoskeleton is involved in "such biological processes as cell shape changes, growth, motility, secretion, and division". The cytoskeleton is clearly important and worth the consideration of any biologist.

Unfortunately, the wealth of information about microtubules, microfilaments, and intermediate filaments makes it very difficult to produce the comprehensive volume which might be expected behind the title Cell and Molecular Biology of the Cytoskeleton. The content of this book is not comprehensive. Many of the chapters are excellent, but each chapter stands in isolation making little contribution to the other chapters in the volume. The overall effect is erratic; for example, actin genes in Caenorhabditis elegans are given a whole chapter; actin genes in mammals are only considered, in passing, during a description of the relationship between actin and cell growth. Before buying this book, carefully scrutinise the contents page to check if a review suitable to your purposes is present.

On one point I can recommend this book without reservation. Just as the devil has the best tunes, cell biologists studying the cytoskeleton have the best photomicrographs. This volume contains some beautiful black and white photographs.

P N GoOdFellow

\section{Mendelian Inheritance in Man}

7th edition. By V A McKusick. (Pp 1741; £58.95.) Baltimore: Johns Hopkins University Press. 1986.

Victor McKusick's Mendelian Inheritance in Man has become such an inseparable companion for any worker in human genetics that its existence and regular updating tend to be taken for granted. Its growth has reflected the growth in our knowledge of genetic disorders, while it has itself helped to shape the developing speciality of medical genetics.

Most of us use Mendelian Inheritance in Man as a reference book, to check on the salient features of some rare or unfamiliar disorder, to provide a list of key references, or to see whether possible heterogeneity in a phenotype is known to exist. For all these functions the book remains indispensable, and the care taken in providing new editions such as the present makes it a resource without parallel.

Another aspect of the book is more often overlooked, and it is this which enhances its value as a book rather than purely as a collection of data. The foreword and appendices address a number of issues central to human genetics, and bring together a number of important facts. The number and proportions of known Mendelian disorders, the table of conditions for which a gene product is known, the current state of the human gene map, and the methods used to define it are a few of the areas where this synthetic aspect of the book shows its value. Similarly, the detailed analysis of particular loci, such as G6PD and haemoglobins, provides a wealth of detail on these systems, while for some of the major disorders, particularly those on the $\mathrm{X}$ chromosome (the origin of the book), the individual descriptions often form the best available short essay on the topic.

For all these reasons the seventh edition is as welcome as its predecessors and, regardless of its future availability in a computerised form 'on line', there is no doubt that it will continue to be a valued companion, to be read as well as consulted.

Peter S Harper

\section{Biochemistry and Biology of Plasma Lipoproteins}

Edited by Angelo M Scanu and Arthur M Spector. (Pp 528; \$107.50.) New York: Marcel Dekker. 1986.

This multi-author volume offers a reasonable overview of recent developments in plasma lipoprotein metabolism. The stated purpose of the book is to highlight the application of new techniques, particularly those of cell and molecular biology, to the study of lipid metabolism and to provide a synopsis and chromosomal location of the apolipoprotein genes, etc. The author list is almost exclusively American and contains many distinguished investigators in the field. However, senior figures in the field, such as Brown and Goldstein and Bryan Brewer, are conspicuous by their absence.

While the book claims to be required reading for a wide spectrum of specialities and interests, ranging from cardiologists and pathologists to geneticists and molecular biologists, my impression is that its appeal will be to a narrower audience. Clinicians of all persuasions will find this book of limited interest as the clinical aspects are dealt with in a more stimulating manner in other, well established texts. This volume will mainly appeal to biochemists, research workers, and scientists working in the field of lipid metabolism. The subject matter is selective but reasonably comprehensive. However, due to the unavoidable delays between the receipt and the publication of contributions, the contents reflect the 'state of the art' up until late 1984 or early 1985 . In such a fast changing field, such considerations become readily apparent.

The style and presentation of the book is functional but unimaginative, often reminiscent of a postgraduate thesis. Minor irritations include the American persistence in measuring lipid concentra- 